\title{
Hepatotoxic Assessment of Co-treatment with Isoniazid and Efavirenz in Albino Rats
}

\author{
Adikwu Elias $^{1, *}$, Brambaifa Nelson $^{1}$, Igbans Rejoice Obele ${ }^{2}$, Odoko J. Onyedenyifa ${ }^{2}$ \\ ${ }^{1}$ Department of Pharmacology, Faculty of Basic Medical Sciences, University of Port Harcourt, Rivers State, Nigeria \\ ${ }^{2}$ Department of Community Health Sciences, College of Health Technology, Bayelsa State, Nigeria
}

Copyright (C) 2015 by authors, all rights reserved. Authors agree that this article remains permanently open access under the terms of the Creative Commons Attribution License 4.0 International License

\begin{abstract}
This study comparatively investigated the toxicological effects of treatment with efavirenz, isoniazid and efavirenz-isoniazid (EFV- INH) combination on liver function parameters and histology of adult male albino rats. Animals used in this study were divided into five (5) groups A-E of sixteen (16) animals each. Animals in group A (placebo control) were treated with water while animals in group B (solvent control) were treated with arachis oil orally. Animals in groups C-E were treated orally with $15 \mathrm{mg} / \mathrm{kg}$ of $\mathrm{INH}, 10 \mathrm{mg} / \mathrm{kg}$ of EFV and a combination of INH- EFV for 2-8 weeks respectively. At the end of drug therapy, serum was extracted from centrifuged blood sample and evaluated for alanine aminotransferase, aspartate aminotransferase, alkaline phosphatase, total and conjugated bilirubin. Animals were sacrificed and liver was harvested, weighed and evaluated for histopathological changes. Effects produced by co-treatment with EFV-INH on absolute liver weight, alanine aminotransferase, aspartate aminotransferase, alkaline phosphatase, conjugated and total bilirubin were insignificant $(p>0.05)$ when compared to effects produced by treatment with individual doses of EFV and INH. Histopathological evaluation of the liver of animals treated with EFV-INH combination showed vascular congestion, inflammation of parenchyma and hepatocytes degeneration. These results show that co- therapy with EFV-INH in patients with human immunodeficiency virus /tuberculosis co-infection may not be associated with synergistic hepatotoxicity.
\end{abstract}

Keywords Liver, Toxicity, Interaction, Isoniazid, Efavirenz, Rats

\section{Introduction}

Human immunodeficiency virus (HIV) pandemic poses major threat to the socio-economic and psychological welfare of HIV infected people with decrease life expectancy. But the life expectancy of HIV-positive subjects has dramatically improved with the use of triple antiretroviral drug combinations [1]. Despite increase in life expectancy of HIV infected patients, toxicological effects of antiretroviral therapy have become a limiting cause of benefit in a substantial proportion of patients. Hepatotoxicity is one of the limiting toxicological effects that has been reported by many centers' in developed world and is now recognized as a major cause of morbidity and mortality in patients receiving antiretroviral treatment [2]. Among antiretroviral drugs, the use of Non- Nucleoside Reverse Transcriptase Inhibitors (NNRTIs), as common component of antiretroviral therapy, has been associated with the development of hepatotoxicity in a large number of studies [3, 4]. Efavirenz is one of the NNRTIs that have been implicated in hepatotoxicity in HIV-positive patients, especially where co-infection with hepatitis viruses is present [5-7]. Several clinical trials have provided information on the frequency of severe hepatotoxicity of grade 3 or above due to efavirenz [8]. Treatment with efavirenz containing antiretroviral regimens could be associated with fulminant liver failure which may lead to death [9].

Tuberculosis (TB) remains one of the most important communicable diseases in the world. The world health organization estimates that one-third of the world's population is infected with mycobacterium tuberculosis. Anti-tuberculosis drugs commonly used for drug-susceptible tuberculosis include isoniazid, rifampicin and pyrazinamide. The use of anti-tuberculosis drugs has been characterized by incidence of hepatotoxicity $[10,11]$. Higher incidence of hepatotoxicity has been commonly reported with the use of isoniazid (INH) containing anti-tuberculosis regimens [12, 13]. Isoniazid could be associated with progressive hepatic failure characterized by alteration in liver histology that may require liver transplantation [14]. Histopathological changes induced by isoniazid therapy were reported to be characterized by ballooning degeneration, and focal hepatocytes necrosis with minimal cholestasis [15]. Also elevations in transaminases have been reported with isoniazid therapy [16]

There are well established epidemiological and biological 
synergies between HIV and TB, influencing the distribution, progression and outcomes of both infections [17, 18]. The established relationship between HIV and TB infections has necessitates co-therapy with antiretroviral drugs and anti-tuberculosis drugs. These include cases of co-therapy with isoniazid containing anti-tuberculosis regimens and efavirenz containing antiretroviral regimens [19]. Efavirenz and isoniazid have been individually implicated in hepatotoxicity $[20,21]$ so; co-therapy with these drugs may cause substantial disruption in the anatomy of the liver which may results in severe alteration in its metabolic roles and physiological functions. This study therefore, comparatively evaluated the toxicological effects of treatment with isoniazid, efavirenz and isoniazid- efavirenz combination on liver function parameters and histology of male albino rats.

\section{Materials and Methods}

Animals

Eighty (80) adult male albino rats of average weight $320 \pm 5 \mathrm{~g}$ were used in this study. The rats were obtained from the animal house of the Department of Pharmacology and Toxicology, Madonna University, Elele, Rivers State. The rats were allowed to acclimatize for 14 days with free access to food and water ad libitum

Ethical Considerations

All animals used in this study were handled in accordance with the international, national and institutional guidelines for care and use of laboratory animals in biomedical research as promulgated by the Canadian Council of Animal Care. [22]

\section{Drugs}

Isoniazid used in this study was manufactured by Mancare Pharmaceuticals, India while efavirenz was manufactured by Mylan Laboratory India. Isoniazid $15 \mathrm{mg} / \mathrm{kg}$ and efavirenz 10 $\mathrm{mg} / \mathrm{kg}$ were used in this study [22-25]. Efavirenz and isoniazid tablets were crushed and suspended in arachis oil. All other chemicals used in this study were of analytical grade.

\section{Drug Administration}

Group A: This served as the placebo control and contained sixteen (16) rats which were treated orally with water.

Group B: This served as the solvent control and contained sixteen (16) rats which were treated with arachis oil orally.

Group C: This group contained sixteen (16) rats which were further divided into four subgroups of four animals each and were treated with $15 \mathrm{mg} / \mathrm{kg}$ of isoniazid orally for 2-8 weeks respectively.

Group D: This group contained sixteen (16) rats which were further divided into four subgroups of four animals each and were treated with $10 \mathrm{mg} / \mathrm{kg}$ of efavirenz orally for 2-8 weeks respectively.

Group E: This group contained sixteen (16) rats which were further divided into four subgroups of four animals each and were treated with combined doses of $15 \mathrm{mg} / \mathrm{kg}$ of isoniazid and $10 \mathrm{mg} / \mathrm{kg}$ of efavirenz orally for 2-8 weeks respectively.

\section{Collection of Sample for Analysis}

At the end of 2, 4, 6 and 8 weeks of treatment respectively, under diethyl ether anesthesia, $2 \mathrm{ml}$ of blood was collected directly via cardiac puncture into sterile sample containers. The sample was allowed to clot and centrifuged at $1000 \mathrm{rpm}$ for $5 \mathrm{mins}$ and serum separated for biochemical analysis. Liver was collected through dissection, weighed and evaluated for histopathological changes.

\section{Evaluation of Serum Liver Function Parameters}

Estimation of aspartate aminotransferase (AST) and alanine aminotransferase (ALT) was done using Reitman-Frankel method 1975 [26]. Estimation of alkaline phosphatase (ALP) was performed using King and Kind Method, 1954 [27]. Total bilirubin (TB) and conjugated Bilirubin (CB) were evaluated as reported by Ogbuehi et al., 2014. [28]

\section{Histopathological Analysis}

For histopathological examinations, pieces of the liver were fixed in $10 \%$ neutral buffered formalin, dehydrated in ascending series of ethanol, cleared in methyl benzoate and embedded in paraffin wax. Paraffin sections of 5 microns in thickness were prepared and stained with hematoxylin and eosin ( $\mathrm{H}$ and $\mathrm{E})$ and examined with the aid of a microscope for histopathological changes.

\section{Statistical Analysis}

This was done using graph pad prism 5 statistical package and ANOVA for comparison of the means of the various groups. Results are expressed as Mean+ standard error of mean (S.E.M). Statistical significance was set at $p<0.05$

\section{Results}

Effects on Absolute Liver Weight and Serum Alanine Aminotransferase (ALT)

Absolute liver weight of animals treated with INH, EFV and INH-EFV combination did not differ significantly $(p>0.05)$ from that of the control. In this study, treatment with INH for 2- 8 weeks time-dependently increased serum ALT levels with significant $(p<0.05)$ increases to $41.2 \pm 0.48$ and $49.5 \pm 0.22 \mathrm{u} / 1$ observed at weeks 6 and 8 respectively when compared to the control. Also, treatment with EFV produced time- dependent increases in serum ALT levels with significant $(p<0.05)$ increase observed at week 8 when compared to the control. It was also noted that co-treatment with INH-EFV for 2- 8 weeks produced time-dependent increases in serum ALT levels. These increases were insignificant $(p>0.05)$ when compared to increases produced by individual doses of IHN and EFV [Table 1 and 2]. 
Table1. Effects of treatment with isoniazid and efavirenz on absolute liver weight $(\mathrm{g})$ of male albino rats

\begin{tabular}{ccccc}
\hline Dose & WK2 & WK4 & WK6 & WK8 \\
\hline Control & $3.22 \pm 0.04$ & $3.29 \pm 0.03$ & $3.30 \pm 0.04$ & $3.21 \pm 0.03$ \\
$\mathrm{INH}$ & $3.30 \pm 0.05$ & $3.27 \pm 0.01$ & $3.24 \pm 0.06$ & $3.26 \pm 0.04$ \\
$15 \mathrm{mg} / \mathrm{kg}$ & & & & \\
$\mathrm{EFV}$ & $3.22 \pm 0.30$ & $3.30 \pm 0.05$ & $3.37 \pm 0.02$ & $3.39 \pm 0.09$ \\
$10 \mathrm{mg} / \mathrm{kg}$ & & & & \\
$\mathrm{INH} / \mathrm{EFV}$ & $3.35 \pm 3.12$ & $3.47 \pm 0.03$ & $3.31 \pm 0.08$ & $3.21 \pm 0.05$ \\
\hline
\end{tabular}

INH: Isoniazid. EFV: Efavirenz. Results are expressed as mean $\pm \mathrm{SEM}$. $\mathrm{n}=4$

Table 2. Effects of treatment with isoniazid and efavirenz on serum aspartate aminotransferase $(\mathrm{U} / \mathrm{L})$ of male albino rats

\begin{tabular}{ccccc}
\hline Dose & WK2 & WK4 & WK6 & WK8 \\
\hline Control & $27.6 \pm 2.21$ & $28.2 \pm 3.13$ & $28.9 \pm 2.14$ & $27.6 \pm 0.14$ \\
INH & $29.5 \pm 1.15$ & $33.1 \pm 2.43$ & $41.2 \pm 0.48^{*}$ & $49.5 \pm 0.22^{*}$ \\
$15 \mathrm{mg} / \mathrm{kg}$ & & & & \\
$\mathrm{EFV}$ & $28.6 \pm 0.65$ & $30.75 \pm 1.14$ & $33.5 \pm 2.51$ & $40.7 \pm 2.23^{*}$ \\
$10 \mathrm{mg} / \mathrm{kg}$ & & & & \\
$\mathrm{INH} / \mathrm{EFV}$ & $31.2 \pm 0.61$ & $33.95 \pm 1.48$ & $43.1 \pm 2.38^{*}$ & $50.3 \pm 0.31^{*}$ \\
\hline
\end{tabular}

$\mathrm{INH}$ : Isoniazid. EFV: Efavirenz. Results are expressed as mean $\pm \mathrm{SEM}$. $\mathrm{n}=4$. The superscript $(*)$ means significant difference with respect to the control at $p<0.05$ (ANOVA).

Effects on Serum Aspartate Aminotransferase (AST)

Furthermore, observations in this study show time-dependent increases in serum AST levels in INH treated animals with significant $(p<0.05)$ increases which represent $42 \%$ and $61 \%$ observed at weeks 6 and 8 respectively when compared to the control. Treatment with EFV also produced time-dependent increases in serum AST levels with significant $(p<0.05)$ increase to $59.7 \pm 1.21 \mathrm{u} / 1$ observed only at week 8 when compared to the control. Time-dependent increases in serum AST levels were noted in animals treated with a combination of EFV-IHN. These time-dependent increases were insignificant $(p>0.05)$ when compared to increases produced by individual doses of EFV and INH [Table 3].

Table 3. Effects of treatment with isoniazid and efavirenz on serum aspartate aminotransferase (U/L) of albino rats

\begin{tabular}{ccccc}
\hline Dose & WK2 & WK4 & WK6 & WK8 \\
\hline Control & $43.0 \pm 3.12$ & $42.9 \pm 1.26$ & $43.1 \pm 2.13$ & $42.7 \pm 1.15$ \\
INH & $45.5 \pm 2.30$ & $50.1 \pm 2.12$ & $61.2 \pm 1.34^{*}$ & $68.5 \pm 1.13^{*}$ \\
$15 \mathrm{mg} / \mathrm{kg}$ & & & & \\
$\mathrm{EFV}$ & $42.3 \pm 1.23$ & $46.75 \pm 2.15$ & $50.5 \pm 0.31$ & $59.7 \pm 1.21^{*}$ \\
$10 \mathrm{mg} / \mathrm{kg}$ & & & & \\
$\mathrm{INH} / \mathrm{EFV}$ & $49.2 \pm 2.00$ & $51.0 \pm 1.22$ & $63.1 \pm 0.18^{*}$ & $69.3 \pm 3.42^{*}$ \\
\hline
\end{tabular}

INH: Isoniazid. EFV: Efavirenz. Results are expressed as mean $\pm \mathrm{SEM}$. The superscript $(*)$ means significant difference with respect to the control at $p<0.05$ (ANOVA). $\mathrm{n}=4$

Effects on Serum Alkaline Phosphatase (ALP)

Time-dependent increases in serum ALP levels were observed in INH treated animals with significant $(p<0.05)$ increases to $84.9 \pm 2.10$ and $92.5 \pm 2.24 \mathrm{u} / 1$ observed at weeks 6 and 8 respectively when compared to the control. EFV treated animals also showed time-dependent increases in serum ALP levels with observed significance $(p<0.05)$ at week 8 when compared to control. Furthermore, treatment with a combination of INH -EFV produced insignificant $(p<0.05)$ time-dependent increases in serum ALP levels when compared to treatment using individual doses of INH and EFV [Table4].

Table 4. Effects of treatment with isoniazid and efavirenz on serum alkaline phosphatase (U/L) of male albino rats

\begin{tabular}{ccccc}
\hline Dose & WK2 & WK4 & WK6 & WK8 \\
\hline Control & $60.9 \pm 1.22$ & $61.5 \pm 2.12$ & $60.7 \pm 0.23$ & $61.9 \pm 2.14$ \\
$\mathrm{INH}$ & $65.5 \pm 1.20$ & $72.3 \pm 1.20$ & $84.9 \pm 2.10^{*}$ & $92.5 \pm 2.24^{*}$ \\
$15 \mathrm{mg} / \mathrm{kg}$ & & & & \\
$\mathrm{EFV}$ & $62.4 \pm 2.10$ & $67.5 \pm 0.32$ & $72.3 \pm 1.20$ & $87.2 \pm 2.13^{*}$ \\
$10 \mathrm{mg} / \mathrm{kg}$ & & & & \\
$\mathrm{INH} / \mathrm{EFV}$ & $67.3 \pm 3.10$ & $72.9 \pm 1.31$ & $86.1 \pm 2.16^{*}$ & $94.5 \pm 1.22^{*}$ \\
\hline
\end{tabular}

INH: Isoniazid. EFV: Efavirenz. Results are expressed as mean \pm SEM. $n=4$. The superscript $(*)$ means significant difference with respect to the control at $p<0.05$ (ANOVA).

Effects on conjugated bilirubin and total bilirubin

Observations in this study show that treatment with individual doses of INH and EFV did not produce significant $(p>0.05)$ effects on serum conjugated and total bilirubin when compared to the control. Also, treatment with a combination of INH- EFV did not produce significant $(p>0.05)$ effects on serum conjugated and total bilirubin levels when compared to effects produced by individual doses of INH and EFV [Table 5 and 6].

Table 5. Effects of treatment with isoniazid and efavirenz on serum conjugated bilirubin $(\mathrm{mg} / \mathrm{dl})$ of male albino rats

\begin{tabular}{ccccc}
\hline Dose & WK2 & WK4 & WK6 & WK8 \\
\hline Control & $0.46 \pm 0.07$ & $0.48 \pm 0.02$ & $0.44 \pm 0.03$ & $0.47 \pm 0.08$ \\
$\mathrm{INH}$ & $0.47 \pm 0.01$ & $0.48 \pm 0.06$ & $0.46 \pm 0.01$ & $0.50 \pm 0.04$ \\
$15 \mathrm{mg} / \mathrm{kg}$ & & & & \\
$\mathrm{EFV}$ & $0.45 \pm 0.03$ & $0.44 \pm 0.08$ & $0.47 \pm 0.04$ & $0.43 . \pm 0.09$ \\
$10 \mathrm{mg} / \mathrm{kg}$ & $0.47 \pm 0.06$ & $0.49 \pm 0.07$ & $0.45 \pm 0.06$ & $0.46 \pm 0.01$ \\
$\mathrm{INH} / \mathrm{EFV}$ & 0.007 \\
\hline
\end{tabular}

INH: Isoniazid. EFV: Efavirenz. Results are expressed as mean \pm SEM. $n=4$

Table 6. Effects of treatment with isoniazid and efavirenz on serum total bilirubin $(\mathrm{mg} / \mathrm{dl})$ of male albino rats

\begin{tabular}{ccccc}
\hline Dose & WK2 & WK4 & WK6 & WK8 \\
\hline Control & $0.83 \pm 0.09$ & $0.85 \pm 0.05$ & $0.80 \pm 0.02$ & $0.85 \pm 0.01$ \\
$\mathrm{INH}$ & $0.84 \pm 0.07$ & $0.86 \pm 0.02$ & $0.82 \pm 0.01$ & $0.84 \pm 0.08$ \\
$15 \mathrm{mg} / \mathrm{kg}$ & & & & \\
$\mathrm{EFV}$ & $0.82 \pm 0.08$ & $0.84 \pm 0.01$ & $0.81 \pm 0.05$ & $0.80 \pm 0.04$ \\
$10 \mathrm{mg} / \mathrm{kg}$ & & & & \\
$\mathrm{INH} / \mathrm{EFV}$ & $0.85 \pm 0.06$ & $0.86 \pm 0.07$ & $0.84 \pm 0.04$ & $0.85 \pm 0.01$ \\
\hline
\end{tabular}

INH: Isoniazid. EFV: Efavirenz. Results are expressed as mean \pm SEM. $n=4$

\section{Effects on Liver Histology}

Histological examination of liver of animals treated with individual doses INH and EFV and a combination of INHEFV showed vascular congestion, inflammation of the parenchyma and degeneration of hepatocytes [Figure 2- 4]. 


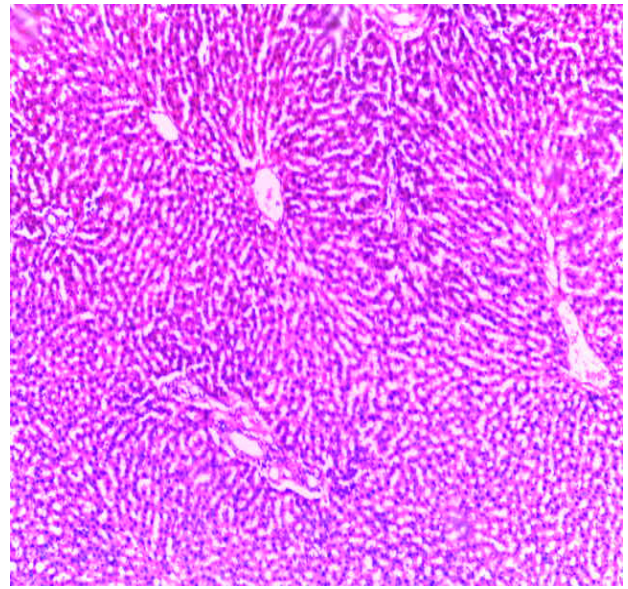

Figure 1: Photomicrograph of $\mathrm{H} \& \mathrm{E}$ stained section of the liver of control rat treated with water. $(\mathrm{x} 400)$

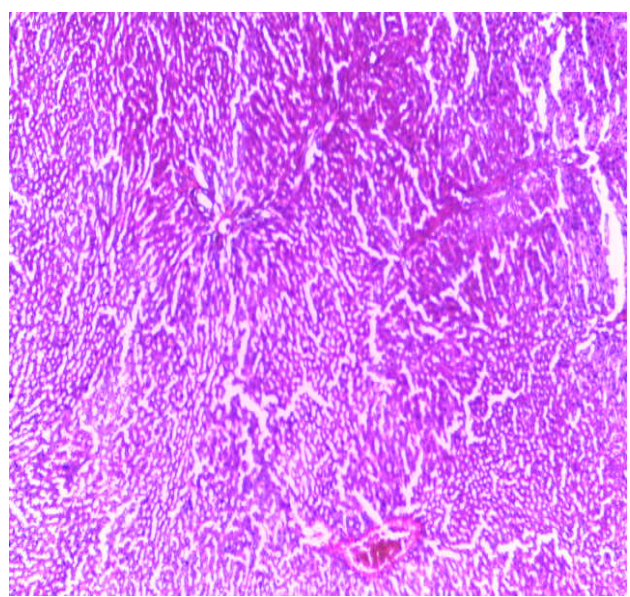

Figure 2: Photomicrograph of $\mathrm{H} \& \mathrm{E}$ stained section of the liver of rats treated with $15 \mathrm{mg} / \mathrm{kg}$ of isoniazid for 8 weeks showing vascular congestion and inflammation of the parenchyma. $(\mathrm{x} 400)$

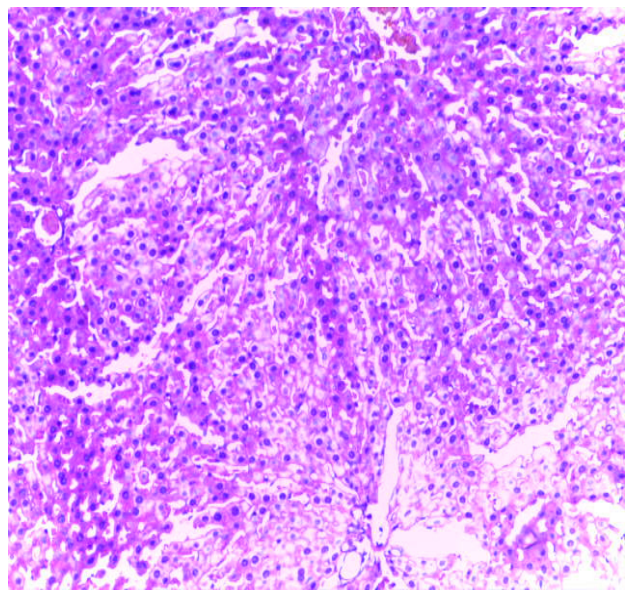

Figure 3: Photomicrograph of $\mathrm{H} \& \mathrm{E}$ stained section of the liver of rats treated with $10 \mathrm{mg} / \mathrm{kg}$ of efavirenz for 8 weeks showing vascular congestion, and degeneration of hepatocytes. (x400)

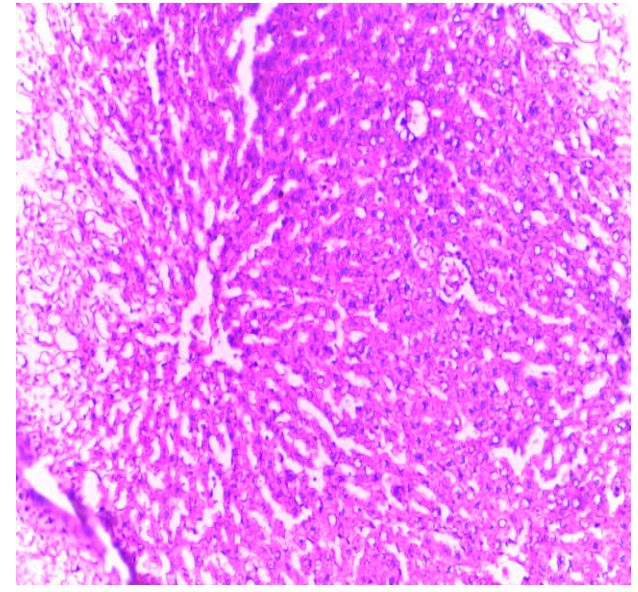

Figure 4: Photomicrograph of $H \& E$ stained section of the liver of rats treated with combined doses of $15 \mathrm{mg} / \mathrm{kg}$ of isoniazid and $10 \mathrm{mg} / \mathrm{kg}$ of efavirenz for 8 weeks showing vascular congestion, inflammation of the parenchyma and degeneration of hepatocytes. (x400)

\section{Discussion}

This study, comparatively evaluated the toxicological effects of treatment with efavirenz, isoniazid and efavirenz-isoniazid (EFV-INH) combination on absolute liver weight, serum alanine aminotransferase (ALT), aspartate aminotransferase (AST), alkaline phosphatase (ALP), conjugated and total bilirubin levels in male albino rats. Effects on the histology of the liver were also evaluated. Toxicological and risk assessment of drugs, chemicals and other biologicals involve organ weight evaluation [29]. In this study, treatment of animals with efavirenz, isoniazid and efavirenz -isoniazid combination had no effects on absolute liver weight. Also, treatment with a combination of efavirenz -isoniazid didn't produce synergistic toxicological effects on serum ALT, ALP, AST, conjugated and total bilirubin levels when compared to effects produced by individual doses of EFV and INH. Histopathological damage characterized by vascular congestion, inflammation of the parenchyma and hepatocytes degeneration were observed in the liver of animals treated with efavirenz, isoniazid and a combination of efavirenz -isoniazid. Observations in this study show that co-therapy with INH-EFV in HIV/TB co-infection may not be associated with synergistic hepatotoxicity. This present study, observed time-dependent increases in serum ALT, AST, ALP levels with no effects on conjugated and total bilirubin levels in EFV treated animals. Observed increases in serum ALT, AST and ALP levels in EFV treated animals suggest signs of liver damage which is consistent with the work of Kayode and others [30-33]. 
In addition to observations in this study, elevations in transaminases due to therapy with EFV have been also reported in humans. One of these reports is the GS 903 study which evaluated 602 naive patients, who were randomized to receive efavirenz containing regimens for 144 weeks and reported grade 3 to 4 increase in ALT and/or AST levels [34]. Bruck et al, also evaluated 296 patients in total, of which 151 received EFV and 145 received NVP, severe hepatotoxicity of grade 3 to 4 elevation in ALT and/or AST was observed in EFV treated patients [35]. This current study also noticed time-dependent increases in AST, AST and ALP levels without any effects on conjugated and total bilirubin in animals treated with INH. These increases in serum levels of ALT, AST and ALP suggest signs of liver damage which is in agreement with the work of Issabeagloo and Taghizadieh, who reported significant increase in liver enzymes in rats treated with INH containing anti-TB regimens for 28 days [36]. Finding in this study is also consistent with the work of Ergul and colleagues who reported increases in liver enzymes in rats treated orally with $50 \mathrm{mg} / \mathrm{kg}$ of INH for 21 days [37]. Swamy and others also reported increases in liver enzymes in rats treated orally with $54 \mathrm{mg} / \mathrm{kg}$ of INH for 30 days which validates our current finding [38, 39]

Furthermore, observed vascular congestion and degeneration of hepatocytes in EFV treated animals is a sign of hepatotoxicity and is consistent with some reported observations [40]. Also, some studies reported EFV associated liver damage characterized by portal and lobular inflammation particularly in zone 2 or 3 with cholestasis in zone 1 [41]. Observed vascular congestion and inflammation of the parenchyma in the liver of IHN treated animal is a sign of hepatotoxicity and is in agreement with reports from previous studies $[42,43]$. Observed increases in serum ALT, AST and ALP levels in this study suggest signs of hepatic damage by these agents which might have led to increase in the permeability of cell membrane or liver systol resulting in the release of these enzymes in to the blood stream [44]. Observed elevation in liver enzymes in INH treated animals may be due to the toxic effects of INH and its metabolites [45, 46]. The metabolism of INH through acetylation and hydrolysis can lead to the production of isonicotinic acid and monoacetylhydrazine (MAH). Monoacetylhydrazine as reported can be converted to hepatotoxic species through interaction with hepatic cytochrome P450 which may be detrimental to the liver. Studies have shown that metabolic oxidation of acetylhydrazine and hydrazine can lead to the production of reactive acetylating species which can bind to hepatic microsomal proteins and induced hepatic damage [47, 48]. Furthermore, available literature implicated INH in the induction of hepatic oxidative stress characterized by increased malondialdehyde level and decreased antioxidants $[49,50]$. The involvement of oxidative stress in INH induced hepatotoxicity is supported by the fact that studies have reported the beneficial effects of treatment with antioxidants in INH induced hepatotoxicity [51-53]. Efavirenz associated hepatotoxicity has been attributed to the actions of EFV and its synthetic 8-hydroxy efavirenz
(8-OHEFV) metabolite. EFV and its metabolite have been implicated in hepatic cell death, via oxidative stress and the activation of caspase-3 [54]. The involvement of hepatic oxidative stress as one of the mechanisms of EFV induced hepatotoxicity is also supported by the work of Alegre and others. They reported EFV up-regulation of hepatic endoplasmic reticulum (ER), oxidative stress markers and induction of morphological changes in ER [55]. Also, Adjene and colleagues have implicated EFV in oxidative stress induction through increased malondialdehyde level and down- regulation of antioxidants [56]. In this present study, elevated levels of transaminases can be correlated with histopathological damage observed in the liver of animals treated with these agents.

\section{Conclusion}

Observations in this study show that treatment with a combination of isoniazid-efavirenz did not produce synergistic toxicological effects on absolute liver weight, liver function parameters and liver histology. This study, therefore conclude that co-therapy with isoniazid and efavirenz in HIV and TB co- infection may not be associated with synergistic hepatotoxicity at the dose level used in this study.

\section{Acknowledgements}

The authors wish to acknowledge the technical assistance of Mr Charles Okeibunor and Mr. Eze Iheukwumere of the Faculty of Pharmacy, Madonna University, Elele, Rivers State, Nigeria

\section{REFERENCES}

[1] AL. Van Sighem, MA. van de Wiel, AC. Ghani, M. Jambroes, P. Reiss, IC. Gyssens, K. Brinkman et al., ATHENA Cohort Study Group. Mortality and progression to AIDS after starting highly active antiretroviral therapy. AIDS, Vol. 17: 2227-2236, 2003

[2] N. Abrescia, M. D’Abbraccio, M. Figoni, A. Busto, E. Butrico, et al., Fulminant hepatic failure after the start of an efavirenz-based HAART regimen in a treatment-naive female AIDS patient without hepatitis virus co-infection. Journal of Antimicrobial . Chemotherapy. Vol. 50 No. 5, 763-765, 2002

[3] MS. Sulkowsky, DL. Thomas, SH. Mehta, RE. Chaisson, RD. Moore. Hepatotoxicity associated with nevirapine or efavirenz-containing antiretroviral therapy: Role of hepatitis $\mathrm{C}$ and B infections. Hepatology Vol. 35: 182-189, 2002

[4] FWN. Wit, GJ. Weverling, J. Weel, S. Jurriaans, JMA. Lange . Incidence and risk factors for severe hepatotoxicity associated with antiretroviral combination therapy. Journal of Infect Disease, Vol. 186: 23-31, 2002

[5] G. Moyle. Efavirenz: shifting the HAART paradigm in adult 
HIV-1 infection. Expert Opinion on Investigational Drugs, Vol. 8, 473-86, 1999

[6] L. Martin-Carbanero, M. Nunez, P. Rios, M. Perez-Olmeda, J. Gonzalez-Lahoz , V. Soriano. Liver injury afterbeginning antiretroviral therapy in $\mathrm{HIV} /$ hepatitis $\mathrm{C}$ virusco-infected patients is not related to immune reconstitution. AIDS, 16: $1423-1425,2002$

[7] MS. Sulkowsky, DL. Thomas, RE. Chaisson, RD. Moore. Hepatotoxicity associated with antiretroviral therapy in adults infected with Human Immunodeficiency Virus and the role of hepatitis C or B virus infection. J Am Med Ass Vol.283: $74-80,2000$

[8] F. van Leth P. Phanuphak, K. Ruxrungthan et al. Comparison offirst-line antiretroviral therapy with regimens including nevirapine, efavirenz,or both drugs, plus stavudine and lamivudine: a randomizedopen-label trial, the $2 \mathrm{NN}$ study. Lancet Vol. 363: 1253-63, 2004

[9] I. Sanne, H. Mommeja-Marin , J. Hinkle et al. Severe hepatotoxicityassociated with nevirapine use in HIV-infected subjects. J Inf Dis Vol.191: 825-9.2005

[10] DP. Taneja, and D Kaur. Study on hepatotoxicity and other sideeffects of antituberculosis drugs. J Indian Med Assoc, Vol. $88: 278-80,1990$

[11] T. Schaberg , K. Rebhan, H. Lode. Risk factors for side-effects ofisoniazid rifampin and pyrazinamide in patients hospitalized for pulmonary tuberculosis. Eurpean Respiratory Journal Vol. 9 : 2026-30, 1999

[12] K. Nanashima, T. Mawatari, N. Tahara, N. Higuchi, A. Nakaura A, et al. Genetic variants in antioxidant pathway: risk factors for hepatotoxicity in tuberculosis patients. Tuberculosis, Vol. 92: 253-259, 2012

[13] S. Santhosh, TK. Sini, R. Anandan, PT. Mathee . Hepatoprotective activity of chitosan against isoniazid and rifampicin-induced toxicity in experimental rats. European. Journal of Pharmacology., 572:69-73. 2007

[14] SS. Wu, CS. Chao, JH. Vargas, HL. Sharp, MG. Martin, SV. McDiarmid, et al.Isoniazid-related hepatic failure in children: a survey of liver transplantationcenters. Transplantation. Vol. 84:173-9, 2007

[15] JR. Itchel, HJ. Zimmerman, KG. Ishak, UP, Thorgeirsson JA, Timbrell Isoniazid liver injury clinical spectrum, pathology, possible pathogenesis. Ann Intern Med Vol. 84; 181-92, 1976

[16] A. Pandit, T. Sachdeva and P. Bafna, Drug-Induced Hepatotoxicity: A ReviewJournal of Applied Pharmaceutical Science Vol. 5: 233-243, 2012

[17] Global report: UNAIDS report on the global AIDS epidemic 2013 [http:/ / www.unaids.org/ en/ media/ unaids/ contentassets/ documents/ epidemiology/ 2013/ gr2013/ UNAIDS_Global_Report_2013_en.pdf

[18] Time to act. Save a million lives by 2015. Prevent and treat tuberculosis among people living with HIV [http:/ / www.stoptb.org/ assets/ documents/ resources/ publications/ acsm/ TB_HIV_Brochure_Singles.pdf

[19] B. J. Larru,Eby, ED. Lowenthal , Antiretroviral treatment in HIV-1 infected pediatric patients: focus on efavirenz Pediatric Health, Medicine and Therapeutics Vol. 5 29-42, 2004
[20] FY. Khan, and F Rasoul . Rifampicin-isoniazid induced fatal fulminant hepatitis during treatment of latent tuberculosis: A case report and literature review. Indian J Crit Care Med Vol.14:97-100, 2010

[21] J. Yue , RX. Peng, J. Yang, R. Kong, J. Liu . CYP2E1 mediated isoniazid-induced hepatotoxicity in rats. Acta Pharmacol Sin Vol. 25:699-704, 2004

[22] International, national and institutional guidelines for care and use of laboratory animals in biomedical research as promulgated by the Canadian Council of Animal Care (2009)

[23] Treatment of Tuberculosis and Tuberculosis Infection in Adults and Children, Am J Respir Crit Care Med Vd (1994); 149. pp 1359-1374

[24] G. K, Bertram Basic and Clinical pharmacology, $9^{\text {th }}$ edition pp818

[25] Goodman and Gilman's. The pharmacological basis of therapeutics $11^{\text {th }}$ Edition, PP. 120-1207.

[26] S. Reitman, and S. A. Frankel, colorimetric method for the determination of serum glutamic oxalacetic and glutamic pyruvic transaminases. American Journal of Clinical Pathology, Vol. 28, 56-63, 1975

[27] E. J. King and P. R. N Kind, Estimation of plasma phosphatase by determination of hydrolyzed phenol with amino-antipyrene. J. Chem. Path. Vol. 7: 322-326., 1957

[28] I. Ogbuehi, E, Adikwu and D, Oputiri. Effect of Acalypha wilkesiana MuellArg Leaf Extract on the Oxidative Indices, Liver Enzymes and Liver Integrity of Rats Infected with Plasmodium berghei , 'British Journal of Pharmacology and Toxicology 5(2): 68-74. 2014

[29] B. Michael, B. Yano, RS. Sellers, R. Perry, D. Morton , N. Roome et al. Evaluation of Organ Weights for Rodent and Non-Rodent Toxicity Studies: A Review of Regulatory Guidelines and a Survey of Current Practices. Toxicol. Pathol. Vol. 35, No. 5:742-750,2007

[30] G. M. Liss., R.A. Greenberg and C.H. Tamburro, Use of serum bile acids in the identification of vinyl chloride hepatotoxicity. Am. J. Med., 78: 68-76, I985

[31] C. Robert and TR. Hustead, Causes and Evaluation of Mildly Elevated Liver Transaminase Level Am Fam Physician., Vol. 84, No. 9, 1003-1008, 2011

[32] R. Manfredi, L. Calza, F. Chiodo. Efavirenz versus nevirapine in current clinical practice: A prospective, open-label observational study. J Acquir Immune Defic Syndr, Vol 35: 492-502, 2004

[33] A. A. Kayode, OT, Kayode, OA, Aroyeu, and MC. Stephen, Hematologic and Hepatic Enzyme Alterations Associated with Acute Administration of Antiretroviral Drugs. Journal of Pharmacology and Toxicology,Vol. 6: 293-302., 2011

[34] JE. Gallant, S. Staszewski, AL. Pozniak, et al. Efficacy and safety of tenofovir DF vs stavudine in combination therapy in antiretroviral-naïve patients: a 3-year randomized trial. JAMA, Vol. 292:191-201, 2004

[35] S. Brück,. And S. Witte, J. Brust D. Schuster, F. Mosthaf, M. Procaccianti, JA. Rump, hepatotoxicity in patients prescribed efavirenz or nevirapine, Eur J Med Res (2008) 13: 343-348 
[36] Y. Issabeagloo, and M Taghizadieh, Hepatomodulatory Action of Camellia sinensis Aqueous Extract against Isoniazid-Rifampicin Combination Induced Oxidative Stress in Rats Advances in Bioresearch, Vol 3:18-27,2012

[37] E Ergul, T. Erkan, H. Uzun, H. Genc, T. Altug andE. Erginoz $\mathrm{E}$, Effect of vitamin $\mathrm{C}$ on oxidative liver injury due to isoniazid in rats Pediatrics International, Vol5. 2, 69-74, 2010

[38] AV. Swamy, RV. Kulkarni, AM. Thippeswamy, BC. Koti, and A. Gore, evaluation of hepatotoxicity activity of cissus quadrangularis sterm extract against isoniazid-induced liver damage in rats. Indian Journal of Pharmacology, Vol. 42; $397-400,2010$

[39] D. Desrochers, RP. González-Peralta, DT. McClenathan, MJ. Wilsey, and A. Haafiz Isoniazid-Induced Severe Hepatotoxicity: An Infrequent but Preventable Cause of Liver Failure in Children Treatedfor Latent Tuberculosis Infection Clinical Medicine Insights: Pediatrics, Vol.5;9-15, 2011

[40] A. Turkova, C. Ball, S. Gilmour-White, M. Rela and G. Mieli-Vergani A paediatric case of acute liver failure associated with efavirenz-based highly active antiretroviral therapy and effective use of raltegravir in combination antiretroviral treatment after liver transplantation Jour of Antimicrob Chem Advance Access published January 22, 2009

[41] MW. Sonderup, H. Wainwright, D. Maughan, M. Setshedi, CW. Spearman Characteristics of Efavirenz drug induced liver injury: a cohort analysis 65th Annual Meeting of the American Association for the Study of Liver Diseases, Boston, MA, USA November 7 - 112014

[42] GI, Qader, R. Aziz, ZA. Ahmed, Z, Abdullah, and SA. Hussain, "Protective Effects of Quercetin against Isoniazid and Rifampicin Induced Hepatotoxicity in Rats." American Journal of Pharmacological Sciences, Vol. 2, no. 3 : 56-60, 2014

[43] C. Singh, J. Laxmikant TD. Bhatt, MS. Gill, S. Suresh S, Hepatoprotective agent tethered isoniazid for the treatmentof drug-induced hepatotoxicity: Synthesis, biochemical and histopathological evaluation Toxicology Reports Vol.1,885893,2014

[44] S. Sarkar, P. Yadav and D. Bhatnagar,. Lipid peroxidative damage on cadmium exposure and alterations in antioxidantsystem in rat erythrocytes: A study with relation to time. Biometals, Vol. 11: 153-157, 1998

[45] EL. Saad, SM. El-Gowilly, MO. Sherhaa, AE. Bistawroos . Role of oxidative stress and nitric oxide in the protective effects of $\alpha$-lipoic acid and aminoguanidine against isoniazid-rifampicin- induced hepatotoxicity in rats.Food Chem. Toxicol.,Vol. 48: 1869-1875, 2010
[46] X. Chen, J. Xu C. , Zhang, T. Yu, H. Wang H, et al. The protective effects of ursodeoxycholic acid on isoniazid plus rifampicin induced liver injury in mice.European. Journal of Pharmacology. Vol. 659: 53-60, 2011

[47] BH. Thomas , LT. Wang, ZW. Zent, G. S Raj, Isoniazid metabolism in the rabbit and effect of rifampicin pretreatment Res Commun, Chem Pathol, Pharmacol Vol. 1, No. $33 ; 235-47,198 \ldots$

[48] A. Noda, h, Hsuky, h. Noda, Y. Yamamoto, T. Kurozumi is isoniazid-hepatotoxicity induced by metabolites hydralazine J. UOEH, Vol.5; 183-90, 1983.

[49] CP. Sodhi, SV. Rana, SK. Mehta, K. Vaiphei, S. Attri, S. Thakur, S. Mehta. Study of oxidative stress in isoniazid-induced hepatic injury in young rats with and without protein-energy malnutrition. J Biochem Toxicol Vol. 11:139-146, 1996

[50] CP. Sodhi, SV. Rana, SK. Mehta, K. Vaiphei, S. Attri, S. Mehta Study of oxidative-stress in isoniazid-rifampicin induced hepatic injury in young rats. Drug Chem. Toxicol. (1997); 20: 255-69.

[51] S. Attri S.V.Rana, K. Vaiphei, CP. Sodhi, R. Katyal, R.C. Goel, CK. Nain, Isoniazid - and rifampicin-induced oxidative hepatic injury - protection by $\mathrm{N}$ - acetylcysteine Human and Experimental Toxicology, Vol. 19 No. 9 517-522, 2000

[52] V. Tayal, BS. Kalra, S. Agarwal, N. Khurana, U. Gupta, hepatoprotective effect of tocopherol against isoniazid and rifampicin induced hepatotoxicity in rabbits. Indian Journal. of Experimental Biology, Vol45; 1031-1036, 2007

[53] S. Baniasadi, P. Eftekhari, P. Tabarsi , F. Fahimi, M R. Raoufy et al. Protective effect of $\mathrm{N}$-acetylcysteine on antituberculosis drug-induced hepatotoxicity. Eur J Gastroenterol Hepatol. Vol, 22, No. 10:1235-8, 2010

[54] N. N. Bumpus Efavirenz and 8-hydroxyefavirenz induce cell death via a JNK- and BimEL-dependent mechanism in primary human hepatocytes.Toxicology and Applied Pharmacology, Vol. 257, No,. 2, 227-234, 2011

[55] F. Alegre, M. Polo, L. J. Go'mez-Sucerquia, H. A. Funes H. B. Garcia, et al., efavirenz induces endoplasmatic stress in human hepatic cells by a mechanism different than that elicited by the pharmacological inducer thapsigargin, Journal of Hepatology Vol. 58, S63-S227, 2013

[56] JO. Adjene, JA. Avbunudiogba, PS, Igbigbi, Oxidative stress induced by chronic administration of Efavirenz on the intracranial visual relay centers of adult Wistar rats Biology and Medicine, Vol. 3 (5): 16-24, 2011 